\title{
Unicystic and Dysplastic Renal Anomalies in a Cadaver
}

\author{
Mathada Vamadevaiah Ravishankar ${ }^{1}$, Vidya C.S. ${ }^{2}$, Sapna Patel M.C. ${ }^{3}$ \\ 1, 2 Department of Anatomy, JSS Medical College, Mysuru, Karnataka, India. \\ ${ }^{3}$ Department of Pathology, JSS Medical College, Mysuru, Karnataka, India.
}

\section{INTRODUCTION}

Kidneys are a pair of excretory organs, which are involved in the expulsion of metabolic waste through urine formation. They play an important role in maintaining the body homeostasis. Evolution of kidney shows its importance in conserving water. Studies on mammalian kidney development have helped in understanding the basic concepts of embryonic development of the urinary system. It helps in early detection and management of congenital renal anomalies. Often such developmental anomalies can be noticed in the patients during their advanced age. One such anomaly was noticed in the dissecting cadavers, showing bilateral developmental defects in the kidneys. The embryological basis and its clinical implications will be considered in the present article.

The development of the urinary system begins with the formation of the nephrogenic cord during $5^{\text {th }}$ week of intrauterine life. It develops from the intermediate mesoderm component of intraembryonic mesoderm; which forms a urogenital ridge, which gives rise to three sets of tubular nephric structures, pronephros, mesonephros, metanephros. Metanephros is the one that contributes to the development of the kidney. There is a complex genetic and molecular interaction between these embryonic tissue components which mutually coordinates for the development of the normal, and functionally viable pattern of the urinary tract. Perturbations of these events lead spectrum of renal congenital defects. ${ }^{1,2}$ Renal Dysplasia is a small kidney with disorganized and undifferentiated structures. Renal Hypoplasia shows small kidney with a lesser number of normal nephrons. Polycystic kidney is a condition with failure in communication between excretory and collecting part leading to the formation of cysts. In the literature these anomalies have been reported even in adults. 3,4 The technology and its application play an important role in the early diagnosis of congenital anomalies and its management in advance.
Corresponding Author: Dr. Mathada Vamadevaiah Ravishankar, Assistant Professor, Department of Anatomy, JSS Medical College, Mysuru, Karnataka, India.

E-mail: ravishmvrs40@gmail.com

DOI: $10.14260 / \mathrm{jemds} / 2020 / 718$

How to Cite This Article: Ravishankar MV, Vidya CS, Patel MC Unicystic and dysplastic renal anomalies in a cadaver. J Evolution Med Dent Sci 2020;9(43):3268-3270, DOI: $10.14260 / \mathrm{jemds} / 2020 / 718$

Submission 27-05-2020,

Peer Review 12-09-2020,

Acceptance 19-09-2020,

Published 26-10-2020.

Copyright (C) 2020 Ravishankar Mathada Vamadevaiah et al. This is an open access article distributed under Creative Commons Attribution License [Attribution 4.0 International (CC BY 4.0)] 


\section{PRESENTATION OF CASE}
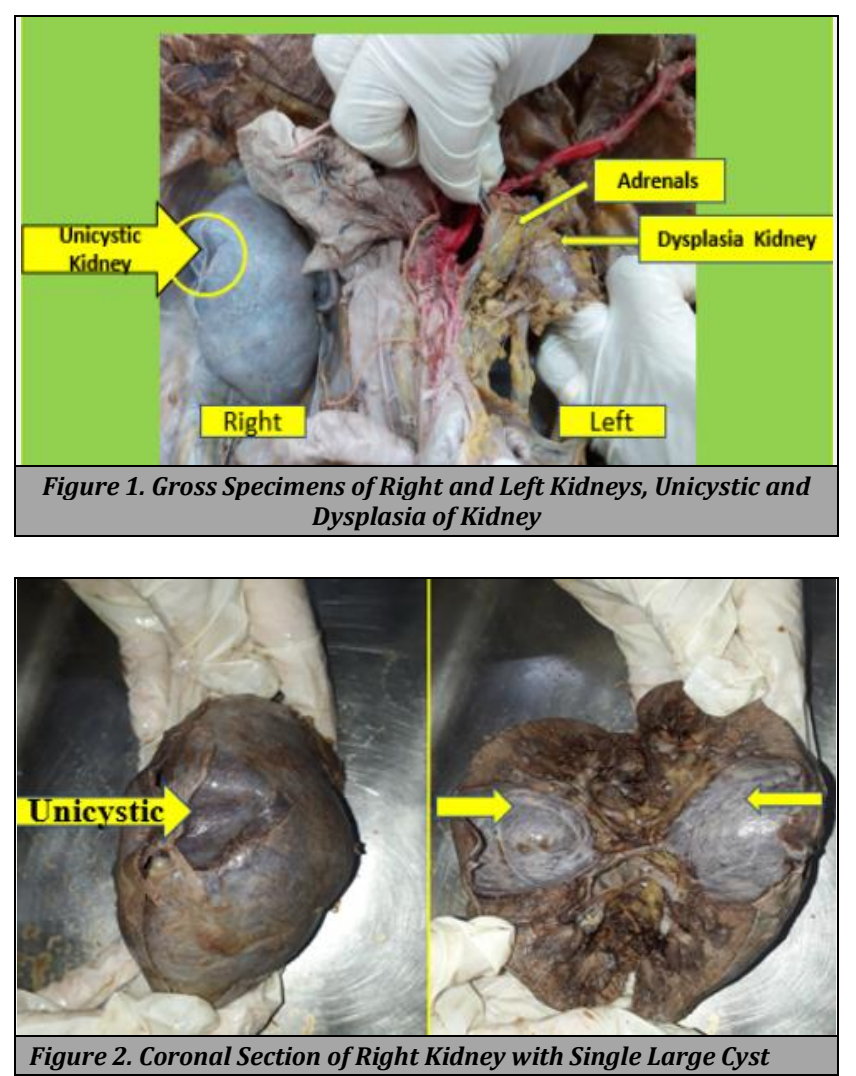

During our routine dissection in the Department of Anatomy, JSS Medical College, Mysuru, Karnataka, in a male cadaver aged around 70 years, we came across an anomalous unicystic (single cystic) right kidney, and an under developed small left kidney was found. (Figure $1 \& 2$ ). Their microscopic features are shown in the photograph. (Figure $3 \& 4$ )

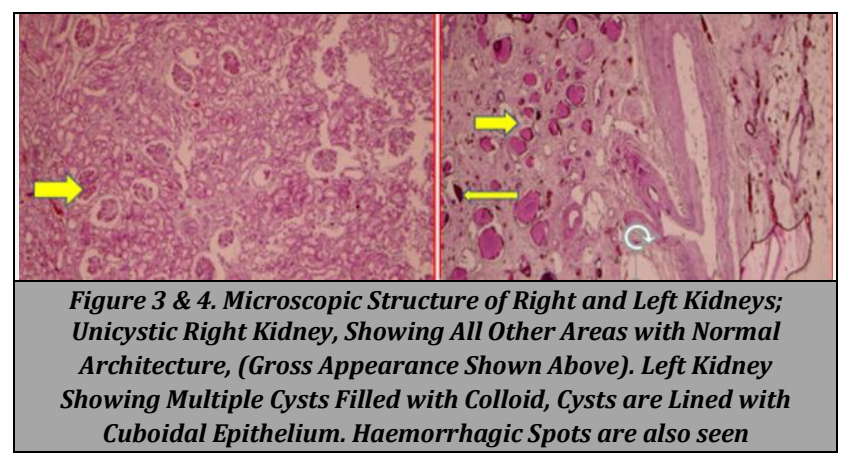

\section{DISCUSSION}

Renal dysplasia is a developmental disorder where the kidney fails to undergo proper differentiation and maturation to achieve its functional viability. Multicystic dysplastic kidney (MCDK) seen 1 in 4000 cases; its incidence is unilateral in 24 $\%$ cases and bilateral $76 \%$ cases; bilateral anomalies are incompatible with life. For the early detection of such anomalies ultrasonography will play an important role.5,6 There are several genes involved in the normal development of kidney like $W T 1, B M P 7$, renin, angiotensin receptor 2, $S A L$ like 1, glypican 3, etc, the expressions of these gene biomarkers are decreased or their disrupted expression profile is seen in dysplastic kidney. ${ }^{7}$

Renal hypoplasia is a congenital defect where one or both the kidneys exist in a smaller size with poorly formed microanatomical features. Bilateral renal hypoplasia is a fatal condition; which is relatively a rare anomaly when compared with the unilateral defect. Kidney morphogenesis requires epithelial and mesenchymal interactions. Renal agenesis is due to faulty molecular signalling interaction between ureteric bud and metanephric blastema. The LIM class homeobox gene Lim 1 is expressed in intermediate mesoderm, primary nephric duct, mesonephric tubules, ureteric bud, and its derivatives. Lack of Lim 1 gene leads to failure in nephric duct formation. This gene is playing an important role in multiple steps of kidney morphogenesis. ${ }^{8}$

Intermediate mesoderm gives rise to the kidney which is marked by the expression of genes pax $2 / 8$; it also depends on molecular signals from the lateral plate and somatic mesoderm. Gdnf regulators are secreted from metanephric mesenchyme which plays an important role in the induction of ureteric bud. Growth and development of kidneys require the cell to cell interactions among induced mesenchyme, stromal cells, angioblasts, and ureteric bud epithelia. Anterior and posterior patterning genes will affect the position of metanephric mesenchyme and proper outgrowth of the ureteric bud. Glomerular development requires diaphragm formation, podocyte differentiation, and type IV collagen formation. ${ }^{9}$

There are several genes involved in the development of kidneys in mammalians; such as Pax2, Eya1, Six1, Six2, Hox11, etc. which are expressed in the mesenchyme which encodes for transcription factors. Mutations in these genes can lead to renal diseases in humans. ${ }^{10}$

Polycystic kidney disease is another genetic disorder, where there is a formation of cysts inside the kidney. Here the collecting renal tubules will become structurally abnormal which fails to connect with the renal corpuscles. These kidneys will be seen larger and will distort the normal architecture of the kidney. There are two types of inherited polycystic kidney disease i.e. ADPKD (Autosomal Dominant Polycystic Kidney Disease) and ARPKD (Autosomal Recessive Polycystic Kidney Disease). ADPKD is a genetic disorder characterized by the formation of cysts in the kidney, which has a family history of the disease. It is caused by mutations in one of the ADPKD1 or $A D P K D 2$ genes. These mutations are inherited by autosomal dominant traits; when the single copy of the abnormal gene is involved. It is associated with the new mutations in genes that normally produce essential protein. These PKD may require treatments like dialysis or renal transplantation. It mostly affects adult males and females equally, in a ratio of 1 in 400 1000 population. This anomalous condition may gradually progress to end-stage renal disease in late adult life. This disorder may be associated with cardiovascular anomalies as well. ${ }^{11}$

ARPKD is caused by mutations of the PKHD genes. This disorder is because of the individual who receives a nonworking gene from each parent. The individual becomes a carrier without any symptoms when they inherit one working and one nonworking gene from parents. PKHD gene expression deals with the formation of a protein called "Fibrocystin". If the patient is having both the copies of the mutated gene causing the suppression of formation of this 
protein results in lethal consequences. If an individual possesses only one working gene for the production of this protein, which can lead to viable urinary defects. ARPKD is seen in children, seen 1 in 20,000 births. It may be associate with some liver anomalies. It may run in families, affecting both genders equally. ${ }^{12}$

Currently, the most common congenital anomalies of the kidney and urinary tract (CAKUT) are associated with a wide range of structural malformations caused by $H N F 1 B$ and PAX2 genes. ${ }^{13}$ Many genes are causing birth defects like congenital heart diseases (CHD) are also linked with the manifestation of anomalies of the renal system. It shows the Commonly Shared genetic etiology for CHD and renal anomalies. ${ }^{14}$

Renal artery stenosis (RAS) is a severe anomaly with a genetic origin. There common gene defect similarity between CAKUT with the anomaly of renal artery stenosis. Tubular renal hypertrophy of renal arteries may be a secondary cause of hypertension; hence renal vascular defects essentially need to be ruled out; where angiography investigation can give a better insight into the anomaly. ${ }^{15,16}$

Radiological investigations play an important role in the detection of CAKUT; it is a group of congenital disorders responsible for the majority of renal anomalies seen among pediatric renal diseases. Two third of CAKUT cases are detected antenatally; ultrasound scanning during the third trimester plays an important role to rule out such early unilateral or bilateral structural defects in the fetus. Most of CAKUT cases are associated with low birth weight and hypertension; its early detection has better prospects in postnatal intervention through surgical standpoint. ${ }^{17}$

\section{CONCLUSIONS}

Renal congenital anomalies should be kept in mind during the medical management and diagnosis of cases presenting with unusual clinical scenarios. Identifying organ anomalies in cadavers during dissections is an illustration of developmental defects. Meeting such anomalies or variations during dissections will certainly create an overwhelming interest among the students to understand and correlate the embryological basis, and its clinical implications.

Financial or other competing interests: None.

Disclosure forms provided by the authors are available with the full text of this article at jemds.com.

\section{REFERENCES}

[1] Mishra S. Urogenital System. Chap- 16. In: Sadler TW, ed. Langman's medical embryology. South Asian Edition Wolters Kluwer 2019.

[2] Weber S, Moriniere V, Knüppel T, et al. Prevalence of mutations in renal developmental genes in children with renal hypodysplasia: results of the ESCAPE Study.J Am Soc Nephrol 2006;17(10):2864-70.

[3] Vikrant S, Parashar A. Autosomal dominant polycystic kidney disease: study of clinical characteristics in an Indian population. Saudi J Kidney Dis Transpl 2017:28(1):115-24.

[4] Raman S, Padhy SK, Rath J, et al. Hypoplastic dysplasia of kidney with hydroureter: two cases. Journal of Clinical and Diagnostic Research 2019;13(6):12-5.

[5] Lazebnik N, Bellinger MF, Ferguson JE, et al. Insights into the pathogenesis and natural history of fetuses with multicystic dysplastic kidney disease. Prenat Diagn 1999;19(5):418-23.

[6] Baker A, Goepfert M, Whitney E. Multicystic dysplastic kidney and sonography: a case report. Journal of Diagnostic Medical Sonography 2017;33(2):120-3.

[7] Jain S, Suarez AA, McGuire J, et al. Expression profiles of congenital renal dysplasia reveal new insights into renal development and disease. Pediatr Nephrol 2007;22(7):962-74.

[8] Kobayashi A, Kwan KM, Carroll TJ, et al. Distinct and sequential tissue-specific activities of the LIM-class homeobox gene Lim1 for tubular morphogenesis during kidney development. Development 2005;132(12):280923.

[9] Dressler GR. The cellular basis of kidney development. Annu Rev Cell Dev Biol 2006;22:509-29.

[10] Brodbeck S, Englert C. Genetic determination of nephrogenesis: the Pax/Eya/Six gene network. Pediatr Nephrol 2004;19(3):249-55.

[11] Autosomal dominant polycystic kidney disease. https://rarediseases.org/rare-diseases/autosomaldominant-polycystic-kidney-disease /

[12] Autosomal recessive polycystic kidney disease. https://rarediseases.org/rare-diseases/autosomalrecessive - polycystic - kidney - disease/

[13] Vivante A, Kohl S, Hwang DY, et al. Single-gene causes of congenital anomalies of the kidney and urinary tract (CAKUT) in humans. Pediatr Nephrol 2014;29(4):695704.

[14] Agustin JTS, Klena N, Granath K, et al. Genetic link between renal birth defects and congenital heart disease. Nat Commun 2016; 7:11103.

[15] Kari JA, Roebuck DJ, Tullus K. Renal artery stenosis in association with congenital anomalies of the kidney and urinary tract. Saudi Med J 2014;35(10):1264-6.

[16] Paz JDN, Burbano JDO, Duque NH. Renovascular hypertension secondary to congenital hypoplasia of renal arteries in middle adult patient. About a case. Rev Colomb Nefrol 2018;5(1):68-73.

[17] Radhakrishna V, Kumaravel S, Priyamvada PS, et al. Clinico-biochemical profile of children with congenital anomalies of the kidney and urinary tract: a crosssectional study. Kidney Dis 2019;5:51-7. 